\title{
Analysis of Gender Responsive Planning and Budgeting (Case Study: Ministry of Finance)
}

\author{
Leisha Wahyu Nurindahsari ${ }^{1 *}$, Trisacti Wahyuni ${ }^{1}$ \\ ${ }^{1}$ Faculty of Economics and Business, Universitas Indonesia, Depok 16424, Indonesia \\ *leisha.wahyu@gmail.com
}

\begin{abstract}
The existence of agreements throughout the world to end all forms of discrimination and to achieve gender equity encourages the implementation of gender responsive planning and budgeting (GRPB). This study aims to provide an overview of the GRPB implementation in the Ministry of Finance (MOF), Indonesia. In addition, this study aims to determine the important factors in the implementation of GRPB, and the steps that must be done to monitor and evaluate GRPB. This research used a qualitative research method with a case-study approach. The case study was conducted at the MOF, which one of the GRPB drivers in Indonesia. The results indicated that an important factor in the implementation of GRPB is an understanding of the concepts of gender, gender mainstreaming, and GRPB. Other things that are critical are leadership commitments, political support, gender analysis tools, and the availability of disaggregated data. Inadequate monitoring and evaluation mechanisms affect the quality of GRPB. The lack of understanding and commitment of the leadership is an obstacle in the implementation of GRPB. However, improved understanding, and adequate monitoring and evaluation processes will improve the quality of the GRPB prepared.
\end{abstract}

Keywords: Gender Responsive Planning and Budgeting; Gender Mainstreaming; Ministry of Finance; Gender Responsive Budget.

\section{INTRODUCTION}

The United Nations (UN) brought into being the Declaration on the Elimination of Discrimination against Women in 1967. To bind the outcome of the declaration, on 18 December 1979 the UN held the Convention on the Elimination of All Forms of Discrimination against Women (CEDAW). The Indonesian government subsequently ratified the results of convention as Law Number 7 of year 1984.

In 1995, the Fourth World Conference on Women was held in Beijing. One of the recommendations in the Beijing Declaration and Platform for Action document explains that UN member states are committed to ensuring equal access and treatment for men and women to achieve gender equity and gender equality. All countries, including Indonesia, agreed to accept the mandate to implement gender mainstreaming in their countries.

At the Millennium Summit meeting in September 2000, world leaders agreed to work together on several targets called millennium development goals (MDGs) with a 2015 deadline. The MDGs were signed up to by 147 heads of state and heads of government, and adopted by 189 countries, including Indonesia. One of the MDG targets is gender equality and women's empowerment. In 2015, the agreement was continued with the setting of sustainable development goals (SDGs), which have a broader target and a deadline of 2030.

To support the target, the Indonesian government issued Presidential Instruction Number 9 of year 2000 on Gender Mainstreaming in National Development. This is a presidential instruction to implement gender mainstreaming for the entire development process (planning, budgeting, implementation, monitoring, and evaluating policies/programs/activities), as an integral part of all government agencies at both central and regional levels.

The implementation of the gender responsive budget (GRB) in Indonesia started from the issuance of a regulation from the Minister of Finance in 2009. In 2012, the National Strategy of Acceleration of Gender Mainstreaming through Gender Responsive Planning and Budgeting (Stranas GRPB) was launched. This regulation uses the term "gender responsive planning and budgeting," which actually means the same as gender responsive budgeting. The Stranas GRPB assigns four drivers, which are the Ministry of National Development Planning / National Development Planning Agency (MNDP), the Ministry of Finance (MOF), the Ministry of Home Affairs (MHA), and the Ministry of Women's Empowerment and Child Protection (MWECP).

The four ministries, which were chosen according to their duties and functions, play a direct role in the implementation of gender planning and budgeting in Indonesia. The MWECP is the ministry that deals with issues related to women's empowerment and child protection. The MNDP is the ministry that plays a role in the preparation of national development plans and controls, and evaluates the implementation of development plans. The MOF's task is organizing government affairs in the field of state finance. Finally, the MHA's duty is organizing internal government affairs, so it plays an important role in implementing gender mainstreaming in local government.

GRB is one of the thematic budgets within the state budget. A thematic budget is the categorization of an output into several themes of budget. GRB has been widely applied in many ministries/institutions and local governments. Various regulations, guidelines, and related guidelines for monitoring and evaluating GRPB have 
been compiled and published, either internally by the MOF or by the MWECP.

However, the implementation of GRPB is not optimal. One of the obstacles is the inadequate reviews, monitoring, and evaluation of the GRPB implementation. This may lead to lower performance in GRPB. The lower performance in the preparation of GRPB will decrease its quality and the goal of GRPB becomes unattainable.

The objective of this research is to provide an overview of the GRPB implementation in the MOF. This study also aims to determine the important factors in the implementation of GRPB, and the steps that must be done to monitor and evaluate GRPB.

This paper is organized as follows. In section 2, the related theories are given. In section 3 , the research method is presented. The research results are presented in section 4. Finally, this paper is summarized in the last section.

\section{LITERATURE REVIEW}

Gender is different from sex. Gender is a socially constructed definition of women and men ${ }^{1}$. The term gender has emerged to explain the natural differences between men and women, and the differences that are cultural constructions that are built, learned, and disseminated. This distinction is very important because human characteristics that are natural and cannot be changed can be confused with human traits that are non-fraternal (gender), and that actually can change or be changed.

Gender mainstreaming is the process of assessing the implications of policies, programs, and legislation on women and men $^{2}$. It can be concluded that gender mainstreaming is a strategy used to achieve gender equality and equity through policies and programs that address the experiences, aspirations, needs, and issues of women and men in the planning, implementation, monitoring, and evaluation processes of all aspects of life and development.

Established organizations have a tendency to homogenize ${ }^{3}$. The concept that best describes the process of homogenization is isomorphism ${ }^{4}$. There are three mechanisms of isomorphism ${ }^{4}, 11$ ) coercive isomorphism, which is the result of both formal and informal pressures placed on the organization by other interrelated organizations and by the cultural expectations of society related to the functioning of an organization; 2) mimetic isomorphism, which is a standard response to uncertainty - when there is uncertainty, an organization tends to imitate other existing organizations; and 3) normative isomorphism, which is associated with professionalism — the pressure that comes from the norms of a particular group to adopt certain institutional practices. This line of research uses insights from organizational institutional theory to explain actions and decision-making in public organizations ${ }^{5}$. For example, the pressure for uniformity comes from normative and mimetic isomorphism ${ }^{5}$.

Public sector budgets, particularly government spending, will affect women and men, both directly and indirectly, as part of general policy ${ }^{6}$. Expenditures are categorized into the following :

1. Gender-specific expenditure, which is a budget that is targeted at the specific needs of women, men, girls, or boys.

2. Expenditures that promote gender equity within the public service, which is a budget that aims to provide equal opportunities for women and men in each organization.

3. General or mainstream expenditures, which is a general budget that provides public goods and services to the society, but it is judged by its impact on gender. This category of budget does not cover both budgets.

The evidence shows that most of government spending (almost 99\%) goes into the third category ${ }^{6}$. Although many governments have special programs for women and men (categories 1 and 2), they are only a small proportion of total government spending and are only budgeted for the short term ${ }^{6}$.

Government budgets are generally arranged without distinction between special budgets for women or men. Therefore, the budget appears to be gender neutral ${ }^{8}$. But if the budget turns out to have a different impact on men and women, then the budget is no longer neutral; if this is ignored, then it is considered to be "gender blindness" Gender responsive budgeting is an important mechanism for ensuring consistency between economic goals and social commitments, as well as providing tools to improve resource-use effectiveness, strengthen economic management, and accelerate gender equality ${ }^{9}$.

The notion of a performance-based budget that uses a variety of performance measures emerges as a workable framework for gender responsive budgets ${ }^{10}$. GRPB is a form of implementing performance-based budgeting, which is managing the planning and budgeting using gender analysis on the inputs, outputs, and outcomes to achieve gender equity and equality as an indicator of performance, after considering the economic aspects, efficiency, and effectiveness ${ }^{11}$.

Gender responsive planning is an effort to integrate gender aspects into the planning process. The planning process is undergone by considering the different needs, issues, aspirations, and experiences of women and men. In gender responsive budgeting, the budgeting process is undergone by integrating the needs of men and women, and aims to achieve gender equity and equality ${ }^{12}$.

In implementing gender mainstreaming, one must use gender analysis techniques. One of the methods of gender analysis developed is the gender analysis pathway (GAP), which is a type of analysis used to identify 
gender gaps by looking at the access, roles, benefits, and controls that men and women have in development programs15. GAP is used to analyse both existing and planned policies ${ }^{11}$.

\section{RESEARCH METHOD}

This research used a qualitative research methodology with a case-study approach. A qualitative approach explains, describes, and summarizes the conditions that arise from the object of in-depth research. The advantage of qualitative research is that it pays attention to the things that can be learned based on evidence in the field, although it is based on the hypothesis and previous theories. In addition, the qualitative approach also allows for the discovery and disclosure of new ideas ${ }^{13}$.

This study was conducted using a case-study approach because the MOF is one of four drivers of GRPB. Case studies include an in-depth and contextual analysis of similar systems in other organizations; i.e., the nature and definition of problems that have occurred in a similar way to those experienced in this situation ${ }^{2}$. In addition, document analysis is also performed. Document analysis is a systematic procedure used to review or evaluate documents, either printed or electronically (using a computer or via the internet) ${ }^{14}$.

The analysis of GRPB completed in this study used an analytical framework ${ }^{6}$. Government budgets are split into three categories to see the amount of budget allocations that gender analysis has undertaken. The data collection techniques used in this study include: literature studies, interviews, and field observation.

\section{RESULTS AND DISCUSSION}

\section{Gender Responsive Planning and Budgeting (GRPB) in the Ministry of Finance (MOF)}

The MOF's GRPB is in line with the Indonesian government's planning and budgeting cycles. GRBs can be categorized into the following ${ }^{12}$ :

1. Gender-equality budget, which is a budget allocated in order to reduce or eliminate the gender gap.

2. Institutionalized gender-mainstreaming budget, which is a budget allocated in order to strengthen the institutionalization of gender mainstreaming, building human-resource capacity, and data collection.

3. Specific gender-targeted budget, which is a budget allocated to fulfil men's or women's basic needs according to results of gender analysis.

GRB implementation in Indonesia is not centered on allocating budgets of certain amounts in order to implement gender mainstreaming. The focus of GRB in Indonesia is, more broadly, that it gives equal access, participation, control, and overall benefits of the budget to both women and men ${ }^{12}$. This principle means that GRB is a budget mechanism used to address the role gaps, status, and responsibilities between women and men. However, GRB is not a separate budget exclusively for women or men; GRB does not mean there are additional budgets specific to women's programs; GRB is not only for women's empowerment programs; GRB does not mean that women and men both receive a 50\% budget allocation for every activity; GRB is not the basis for requests for additional budget allocations; and not all programs and activities must be amended to be gender responsive because there are activities that are gender neutral.

Monitoring and evaluation activities are used to identify the constraints and activities/interventions needed to improve future implementations ${ }^{15}$. The scope of GRPB monitoring and evaluation relates to budget documents. The monitoring and evaluation of GRPB is tiered, based on gender mainstreaming pre-requisites (i.e., rules, institutionalization, human-resource capacity, disaggregated data, and budgeting).

\section{Important Factors in Gender Responsive Planning and Budgeting (GRPB)}

Based on the results of the research, the factors affecting the implementation of GRPB include humanresource capacity, leadership commitment, political support, gender analysis tools, and availability of disaggregated data.

The most influential factor in the implementation of GRPB is improving human-resource capacity (planning and budgeting staff), which comes from understanding the concept of gender, gender mainstreaming, and GRPB. Without a good understanding, planning and budgeting staff will find it difficult to integrate gender issues and it will potentially cause employee resistance. Employee resistance, in this instance, could be the unwillingness of employees to implement GRPB because, in their perception, the concept of gender contradicts religion and violates nature. If planning and budgeting staff have a good understanding, they will directly integrate gender perspectives into the planning and budgeting processes. Increasing understanding at the level of leadership will increase the leadership's commitment to implementing gender mainstreaming through GRPB. These results are in line with previous research ${ }^{7,10,16}$.

Leadership commitment also affects the implementation of GRPB. In this case, leadership commitment can be in the form of instructions to the technical unit under their leadership to integrate gender issues into planning and budgeting for their duties. Leadership commitment is identified as an influential factor in much previous research $^{7,8,12,16,17}$. The important factors in the implementation of GRPB are the roles of leaders, especially leaders 
of budgeting and policy-making units ${ }^{6}$. If both internal and external stakeholders have seen a gender gap, and agree to reduce or eliminate the gap, then they will change their mindset and even influence the process of allocating resources ${ }^{8}$.

Political support in the form of regulations governing GRPB is also important in implementing GRPB. Presidential Instruction Number 9/2000 is a clear rule that gender issues should be integrated into every aspect of development. This is reinforced by the MNDP in that national priorities are supported by several types of mainstreaming and one of this was gender mainstreaming. The existence of political support will help to maintain the sustainability of GRB implementations. This factor in line with Dena's research results ${ }^{3}$. This form of political support in the implementation of GRB is also shown by various international organizations and non-governmental organizations in the form of assistance and funding ${ }^{18}$.

The next factor that affects the preparation of GRPB is a gender analysis tool, which is used in an attempt to identify issues of gender. The gender analysis tool that has been used is GAP. To simplify, the MOF have integrated GAP into its gender budget statement (GBS), so that GRPB can be instantly viewed on a single document. Based on this research, gender analysis tools such as GAP have not been overly used in the preparation of the budgets. Some respondents do not know even about GAP. The use of GAP as an analytical tool is considered to be too complicated. The respondents generally conduct a gender analysis with reference to the GBS.

Another important factor in GRPB is availability of disaggregated data. Because its availability is required to conduct a gender analysis. Without disaggregated data, it is difficult to determine the gender gap that occurs.

Based on the institutional theory, political support and the commitment of the leadership can be associated with coercive isomorphism. Implementing GRPB is one form of reacting to pressure from the outside from various international agreements (which include Indonesia) to eliminate the gender gap. The external pressure on the Indonesian government also comes from people who have asked for basic human rights. Gender responsive policies are the result of political support and the commitment of the leadership. Regulations regarding GRPB cause external pressure on the MOF to implement it.

The implementation of GRPB is required as a result of the various GRPB-related government regulations, so all elements of the government will try to implement it. Organizational commitment can be associated with normative isomorphism.

Gender analysis tools are selected using various processes, including benchmarking and seeing the successful implementation of GRB in other countries. Therefore, the choice of gender analysis tools can be associated with mimetic isomorphism.

\section{Gender Responsive Budget Analysis}

According to the research, the MOF still lacks documentation for gender responsive activities. Many of the regulations and the activities already conduct an analysis of gender accommodated activities to avoid a gender gap that is not documented through GBS. A GBS is created when there is still a gender gap, and activities will be completed to reduce or eliminate the gap. In terms of perceived benefits, all respondents acknowledged many positive impacts from gender mainstreaming.

Based on the GBS data from the MOF (years 2010 to 2017), there has been an increase in the number of GBSs and the value of rupiahs budgeted after gender analysis was conducted. There has been an increase in the number of GBSs prepared in the MOF every year. Increasing the amount of GBSs prepared does not necessarily mean that there will be budget allocations for these activities.

The GRBs implemented by the Indonesian government, based on GBS data and the MOF's budgets (20102017) show that the highest percentage of GRBs occurred in 2013, which was $2.28 \%$. Based on the framework developed by Sharp and Broomhill, the MOF's budget is grouped into three categories. The categories for gender specific expenditure and expenditure that promotes gender equity are derived from the GBS data, and grouped into activities devoted to the specific needs of each gender, and activities aimed at providing equal opportunities for female and male employees in each organization. However, the budgets that do not fall into either of these two budget categories are included in the general category.

A total of $99 \%$ of the government's budget is included in the third category ${ }^{6}$. The two other budget categories only account for $1 \%$ of the government's budget. From the $99 \%$ of the government's budget, it should be possible to analyse the impact for the community. The question to be asked is whether all people in the community have equal access, participation, control, and benefits. If not, it needs to be determined who are benefiting the most from the preparation of the budget.

\section{Monitoring and Evaluating Gender Responsive Planning and Budgeting (GRPB)}

Based on the results of the research, the monitoring and evaluation of GRPB is considered to be inadequate, since it is limited to only checking the completeness of the GBSs (the documentation for GRBs) as one of the supporting budget documents, while the quality of the GBSs has not been considered. 
Related to the inadequate evaluation in the preparation of GRBs, the MOF's Directorate General of Budgets asserts that, in the case of budget reviews, it examines all types of budgets, including thematic budgets, based on the budgetary planning rules, and there is no special review for thematic budgets. The review of GBSs should be done by the Planning and Budgeting Bureau for internal reviews at the level of the MOF and by the MNDP at the national level. However, evaluating the implementation of GRPB is a duty of the MWECP. This is in based on the division of tasks in the Stranas GRPB. Furthermore, assistance from the MWECP in preparing the GBSs is considered important.

The evaluation of GRB at the national level is only checking the availability of GBSs. The MNDP does not specifically discuss the gender analysis of the action plan that has been drawn up by each unit. As a result, the Planning and Budgeting Bureau also do not examine the quality of GBSs delivered by each echelon. It is expected that the role of the regulator or the driver of GRPB must be clarified, thus increasing enthusiasm in arranging GRPB.

GRPB monitoring and evaluation has not been implemented independently by each echelon or work unit. The main problems of monitoring and evaluating GRPB internally are related to limited human resources and the lack of direction from the leadership (leadership commitment).

The evaluation is also done through the implementation of a gender mainstreaming contest. The purpose of this competition is to maintain the implementation of gender mainstreaming and for evaluation purposes. This competition is welcomed, but the main obstacle encountered is that not all units participate in this competition.

\section{CONCLUSION}

Based on the research, the factors that are considered to be influential are the improvement of humanresource capacity (especially planners and budget compilers), political support, leadership commitment, and availability of disaggregated data. Political support and the commitment of the leadership can be associated with coercive isomorphism. Organizational commitment can be associated with normative isomorphism. Gender analysis tools can be associated with mimetic isomorphism.

The diversity of the GRPB mechanisms used in each echelon is one of the effects of the lack of understanding of the concepts of gender, gender mainstreaming, and GRPB. It also affects the policies taken by the head of each echelon related to the application of GRPB in each unit.

Based on the results of this research, the monitoring and evaluation of existing GRPB is considered to be inadequate because it is limited to monitoring the availability of GBSs, and does not assess the quality of the GBSs prepared. The respondents expect monitoring and evaluation during the GBS preparation as well as after the implementation of activities. Monitoring at the time of preparation should be conducted to improve the quality of the GBS prepared, so that the GBS is not just a formality. The evaluation of the GRPB implementation is required to be more comprehensive; for example, by looking at whether the performance indicators for the GBS are achieved or not.

\section{REFERENCES}

[1] Council of Europe. Gender mainstreaming - Conceptual framework, methodology and presentation of good practices. Final Report of Activities of the Group of Specialists on Mainstreaming, Strasbourg (1998).

[2] R. K. Yin. Qualitative research from start to finish, The Guilford Press, New York (2010).

[3] M. K. Dena. Public budgeting with a gender lens: Fulton County, Georgia and San Francisco, California. Dissertation, University of Texas (2013).

[4] P. J. DiMaggio and W. W. Powell. The iron cage revisited: Institutional isomorphism and collective rationality in organizational fields. American Sociological Review, 48(2)(1983) 147-160.

[5] A. R. Villadsen. Structural embeddedness of political top executives as explanation of policy isomorphism. Journal of Public Administration Research and Theory, 21(4)(2011) 573-599.

[6] D. Budlender, R. Sharp, K. Allen. How to do a gender-sensitive budget analysis: Contemporary research and practices, Commonwealth Secretariat and AusAID, London (1998).

[7] D. Budlender, D. Elson, G. Hewitt, T. Mukhopadhyay. Gender budgets make cents - Understanding gender responsive budgets, Commonwealth Secretariat, London (2002).

[8] M. M. Rubin, J. R. Bartle. Integrating gender into government budgets: A new perspective. Public Administration Review, 65(3)(2005) 259-272.

[9] G. Hewitt, T. Mukhopadhyay. Gender budgets make cents - Promoting gender equality through public expenditure, Commonwealth Secretariat, London (2002).

[10] R Sharp. Budgeting for equity: Gender budget initiatives within a framework of performance oriented budgeting. United Nations Entity for Gender Equality and the Empowerment of Women, New York (2003).

[11] Ministry of National Development Planning/National Development Planning Agency. Gender Analysis Pathway (GAP): A gender analysis tool for development planning, Jakarta (2007).

[12] Ministry of Finance. Guidelines of responsive gender planning and budgeting in Ministry of Finance, Jakarta (2010).

[13] U. Sekaran. Research methods for business: A skill-building approach 4th edition, Wiley India Pvt. Limited, India (2006).

[14] G. A. Bowen. Document analysis as a qualitative research method. Qualitative Research Journal, 9(2)(2009) 27-40.

[15] Ministry of Finance. Guidelines of monitoring and evaluation of gender responsive planning and budgeting in Ministry of Finance, Jakarta (2012). 
[16] J. R. Bartle, M. M. Rubin., S. Issarachaiyos. The challenge of implementing gender budgets. Public Administration Faculty Proceedings and Presentations, Paper 2 (2008).

[17] D. Elson. Gender budget initiatives: Strategies, concepts and experiences, The United Nations Development Fund for Women, New York (2001).

[18] ILO Bureau for Gender Equality. Overview of gender-responsive budget initiatives, International Labour Organization (2006). 